Interpersonal trust in organisations: an empirical investigation of workplace outcomes in two countries

\author{
Aziz Bakay* \\ Department of Logistics Management, \\ Gediz University, \\ Gazi Mustafa Kemal Mh. Kaynaklar Cd., \\ No: 115, B-227, Seyrek, Menemen, \\ İzmir 35665, Turkey \\ Email: aziz.bakay@gediz.edu.tr \\ *Corresponding author

\section{Bülent Akyüz} \\ Department of Business and Management, \\ Çanakkale Onsekiz Mart University, \\ Terzioğlu Yerleşkesi, \\ Çanakkale 17200, \\ Turkey \\ Email: bakyuz@comu.edu.tr
}

\author{
Abidin Ateş \\ Department of Management, \\ Gediz University, \\ Gazi Mustafa Kemal Mh. Kaynaklar Cd. \\ No: 115, B-225, Seyrek, Menemen, \\ İzmir 35665, Turkey \\ Email: abidin.ates@gediz.edu.tr
}

\begin{abstract}
This research hypothesised that particular workplace behavioural outcomes can be explained by interpersonal trust, considering the traditional perspectives on trust as a social glue lowering transaction costs. We employed an approach of distinguishing three trust objects, namely, trust in peers, trust in the supervisor, and trust in top management. Survey data on interpersonal trust, affective commitment (AC), intention to turnover (ITT), job satisfaction (JS) and job performance (JP) was collected from professionals working in Turkey $(\mathrm{N}=134)$ and the USA $(\mathrm{N}=150)$. Data were analysed using partial least square based structural equation modelling. Findings in general suggested a normative point of view of trust, and discussions from comparative cultural contexts were given. Evidence shows that AC was positively associated with trust in peers and trust in top management in both countries. JS was explained by trust in supervisors in the US sample, whereas trust in top management predicted JS in the Turkey sample. ITT, due to its economic-grained nature, did not associate with any of the trust variables, implying the distinction between social exchange and economic exchange. JP and trust were inversely associated in the samples from both countries, revealing a team effect and contradicting the initial hypothesis. Practical implications were discussed.
\end{abstract}


Keywords: cross-cultural trust; interpersonal trust; organisational behaviour; PLS based SEM.

Reference to this paper should be made as follows: Bakay, A., Akyüz, B. and Ateş, A. (2016) 'Interpersonal trust in organisations: an empirical investigation of workplace outcomes in two countries', European J. Cross-Cultural Competence and Management, Vol. 4, No. 2, pp.116-145.

Biographical notes: Aziz Bakay, Assistant Professor, received his $\mathrm{PhD}$ in International Business Administration from Texas A\&M International University. He has published in the fields of decision making, management, organisation and international business. His current research includes entrepreneurship, social identities, and intergroup relations within organisational contexts.

Bülent Akyüz is an Assistant Professor of Management and Organisation Studies in the Faculty of Economics, Business and Administration at Çanakkale Onsekiz Mart University. He received his $\mathrm{PhD}$ in Management and Organisation from Gebze Institute of Technology. His current research interests include management, leadership, organisational behaviour, total quality management, strategic management, human resource management, and international relations.

Abidin Ateş is pursuing his $\mathrm{PhD}$ degree in Management at Gediz University. His current research interests include management, financial accounting, environmental accounting, and corporate governance.

This paper is a revised and expanded version of a paper entitled 'Trust in peers, supervisor, and top management: A research on workplace outcomes', presented at Lamar Bruni Vergara/Guillermo Benavides Z. Academic Conference, Laredo, TX, USA, April 19-20, 2012.

\section{Introduction}

Businesses today with global implications pose interdependence of components in complex organisations (Thompson, 1967). The changing nature of the workplace, with its increasing diversity, dissimilar individuals sharing the same office space, and technological breakthroughs creates 'revolutions' in our lifestyles, making it an everyday duty to be in contact with numerous employees and colleagues in tackling interpersonal issues inside and outside of the organisation (Cascio, 1995). As Mayer, Davis and Schoorman (1995) noted, interactive behaviour with members of the business enterprise or the organisation imposes cooperation and reliance on each other. Considering the increasing uncertainty and complexity of organisational environments and healthy relationships, interpersonal trust is considered necessary for successful function (Luhmann, 1979). The uncertainty that employees face can be reduced by the existence of interpersonal trust. 
Interpersonal trust forms stable social relations, allowing individuals to increase their input to the organisational processes and effectiveness (Blau, 1964). Similarly, it functions as a lubricant for interactive behaviour, and thereby, lowers transaction costs, leveraging efficiency (Putnam, 1993). Social exchanges suggest that reciprocal obligations arise as exchanges among parties take place (Blau, 1964). The expectation of 'paying back' gives a feeling of confidence in an interdependent situation. Touching upon social exchange, reciprocity, social relations, and uncertainty, this study aims to empirically explore associations and the explanatory power of interpersonal trust on particular organisational behaviours that have not been thoroughly studied in references to trust in the literature. Regarding the cross-cultural context of interpersonal trust (Ward, Mamerow and Meyer, 2014; Yamaguchi, Brase and Yama, 2014), many recent studies have suggested that trust is associated with different organisational outcomes such as performance (Afzal and Afzal, 2014; Paliszkiewicz, Koohang and Nord, 2014); employee attitudes (Powell and Ferguson, 2014); commitment (Jiang, Gollan and Brooks, 2015); stress and satisfaction (Guinot, Chiva and Roca-Puig, 2014); and intention to turnover (ITT) (Balkan, Serin and Soran, 2014). Due to the important implications of trust with regard to individual and organisational effectiveness, investigating the particular psychological state of trust and its behavioural and attitudinal outcomes becomes crucial in organisational behaviour research. This research examines interpersonal trust in two countries, allowing for comparison based on national cultural characteristics.

The current research contributes to the knowledge of interpersonal trust and its associations with workplace outcomes, namely, affective commitment, intention to turnover, job performance and job satisfaction. Prior literature suggested that the prevalence of trust in interpersonal relations in organisations as well as its function as a lubricant of the social fabric possesses importance (Putnam, 1993). The normative point of view of trust as 'good' and distrust as 'bad' (Erikson, 1963) has been examined in the current research and empirical findings bring new evidence for this notion.

\section{Literature review}

Trust can be defined as "confidence in the integrity and reliability of another party, rather than confidence in the partner's ability to perform a specific action" (Hausman and Johnston, 2010). McAllister (1995) defines interpersonal trust as "the extent to which a person is confident in and willing to act on the basis of, the words, actions and decisions of another".

The foundation of the trust conceptualisation in this study is the vulnerability perspective. The definition of interpersonal trust embraced in this research is "willingness of a party to be vulnerable to the actions of another party based on the expectation" (Mayer, Davis and Schoorman, 1995, p.712). The willingness to be vulnerable and to take risks as the definition of trust entails a pro-active involvement with regard to individual behaviour.

We elaborate on interpersonal trust constructs in our theoretical framework on a highlow scale which surfaces after an individual's cognitive effort in a trust situation. All of the interpersonal interactions settle into a level of trust as a one-dimensional consequent psychological state. Therefore, trust phenomena could be understood in a bipolar continuum; (i.e., high/low trust). In line with this standpoint, the present study 
operationalises the bipolar trust attitude among truster and trustee, drawing from the balance and consistency view.

The approach of balance and consistency provides a useful outlook for understanding the behavioural phenomenon and trust in particular. This research stream has foundations in Festinger's (1957) theory of dissonance and Heider's (1958) work on the psychology of interpersonal relations. This view proposes that human behaviour has a homeostatic nature and avoids any psychological imbalance and inconsistencies in a relational situation. An individual tends to either like or dislike, either trust or distrust. The reasoning is that there is an attempt to avoid inconsistent cognitions due to the other party and/or others' behaviour, resulting in a homogenous behaviour and attitude.

\subsection{Generalised trust in cross-cultural surveys}

Referring to dispositional trust, a number of cross-national studies attempted to capture the level of generalised trust. The World Value Survey (WVS) depends on a single question in order to measure trust across cultures. One of the earlier generalised trust measures developed by Rosenberg (1956) is the following one-item question: "Generally speaking, would you say that most people can be trusted or that you need to be very careful in dealing with people?" Analysing the answers (1- most people can be trusted; 2-cannot be too careful; 3- do not know) for this question, WVS provides a cross-national dataset that enables researchers to assess the correlations of generalised trust with relevant macro-level variables (Morrone, Tontoranelli and Ranuzzi, 2009). By the same token, the General Social Survey includes two items and the European Social Survey includes three items tapping on the generalised trust that were measured in the USA and in European countries, respectively ${ }^{1}$. As such, Uslaner (2002) highlighted the correlation between the level of generalised trust and economic inequality. Besides, a causal relationship is implied from the income distribution of the country towards trust. Further, out-group members are more favoured by the high generalised trusters.

Considering WVS data ${ }^{2}$, Turkey (10.2) scores very low on the trust index, ranking $116^{\text {th }}$, whereas the USA is moderately high (78.8), ranking $19^{\text {th }}$ in the world. The underlying motivation for the current study is partially based on the need for exploration of the trust phenomenon in the country of Turkey, where seminal studies report an extreme low score of generalised trust. Considering the distinction between generalised and interpersonal trust, the current research, with the empirical test of two models using samples from two countries, will generate further insights about the central trust variables and their implications for particular organisational behaviour.

Multiple relationships involving trust exist within organisations, among which we consider trust in peers, in supervisors, and in top management. All three referents constitute important facets of work life within organisations, which leads us to expect that each type of trust will have its own distinctive effect. In the current research, therefore, we test whether these three types of trust are positively associated with organisational behaviour and attitudinal outcomes. As such, AC, ITT, JP, and JS of the employees are explored, benefiting from the balance and consistency view. 


\subsection{Trust and affective commitment}

$\mathrm{AC}$ is included as one of the behavioural outcome/dependent variables because of its conceptualisation and its relevance to emotional attachment, and because of empirical evidence (Bateman and Strasser, 1984; McAllister, 1995; Meyer and Allen, 1997; Yang, 2005) showing its strong connection and predictive power with workplace outcomes. Meyer and Allen (1997) addressed that considering a professional employee with strong $\mathrm{AC}$, the individual is expected to have higher motivation and desire, which will contribute to the organisation indirectly.

The literature suggests that there is a positive correlation between $\mathrm{AC}$ and trust in organisational members. Ferres, Connell and Travaglione (2004) affirmed with empirical evidence that co-worker trust has explanatory power on affective organisational commitment. Yang (2005) stated that affective trust in management was positively and significantly related to affective organisational commitment in two medical centres in the South-eastern USA. Michaelis, Stegmaier and Sonntag (2009) found empirical support for the relationship between employees' trust in top management and AC to change, using data on 194 employees working in the R\&D teams of a multinational automotive company. Examining supplier-customer relationships in high-technology markets, de Ruyter, Moorman and Lemmink (2001) reported the positive predictive power of trust in AC. Additionally, Kaneshiro (2008) found that in a single public organisation, organisational justice and organisational trust (i.e., trust in management/top management) are significantly related to organisational commitment. Based on the literature above:

H1: Trust in peers is positively associated with affective commitment.

H2: Trust in supervisor is positively associated with affective commitment.

H3: Trust in top management is positively associated with affective commitment.

\subsection{Trust and ITT}

ITT measures to what extent the individual is willing to quit his/her current job. Due to the costly implications of turnover in organisations, organisational behaviour that undermines such an intention and strengthens the employees' tendency to stay with the organisation should be addressed. ITT has been investigated in many organisational behaviour research studies (Allen and Meyer, 1996; Glissmeyer, 2010; Mathieu and Zajac, 1990; Tett and Meyer, 1993).

Davis et al. (2000) researched branches of a restaurant chain and attempted to capture the relationship between trust in the general manager and turnover and business unit performance in terms of sales and profit. The trust in general managers predicted the profits and sales of restaurants, controlling for restaurant size, household, and median income. The results suggested that the difference in turnover between highly trusted general managers and poorly trusted general managers is marginally significant, implying that restaurants that have trusted general managers were found to have lower turnover. Ferres, Connell and Travaglione (2004) focused on co-worker trust and its relation to organisational perceptions and attitudes. Co-worker trust significantly predicted the perceived organisational support and $\mathrm{AC}$ to the organisation, undermining ITT. 
Distinguishing the trust referents, Tan and Tan (2000) investigated trust in the supervisor and trust in the organisation. Their results suggested that trust in the supervisor was connected to the characteristics of the supervisor, referring to the ability, benevolence, and integrity. Besides, trust in the organisation is highly associated with the procedural and distributive justice, as well as lower ITT and higher organisational commitment. Luis (1995) examined an archival database of 807 employees at a large aerospace corporation and found a strong association between trust in management and ITT. A meta-analysis by Dirks and Ferrin (2002) supported the negative causal link $(r=-0.40)$ between trust and intention to quit by examining 17 samples amounting to 3,297 observations. Based on the discussions above:

H4: Trust in peers is negatively associated with ITT.

H5: Trust in supervisor is negatively associated with ITT.

H6: Trust in top management is negatively associated with ITT.

\subsection{Trust and job performance}

JP in the current study is viewed as the extent to which an individual assesses his/her own performance compared to the performances of his/her colleagues in the organisation. There are numerous aspects of work that might be relevant to individual JP, and thus, we limit the conceptualisation of the construct and focus on an individual's self-assessment of quantity and quality of output, efficiency in work, adjustment and handling quality to work changes, and handling of work emergencies (Mayfield and Mayfield, 2006). Our theoretical model hypothesises that there is a positive association between individual JP and three trust variables: trust in peers, trust in supervisors, and trust in top management. Departing from the discussion of trust as a social glue (Erikson, 1953; Putnam, 1993) that minimises inefficiencies and lowers transaction costs in professional relations, the expected impact of interpersonal trust on JP is positive. Our theoretical model aims to explore individual impacts of the three trust referents on JP. Thereby, depending on the findings for practitioners and researchers, a beneficial point of view for individual and organisational effectiveness is presented. As such, one can channel the efforts of establishing interpersonal trust towards particular organisational members, which would eventually pose relatively higher importance.

With respect to trust in direct leaders/supervisors, Rich (1997) found empirical support for the relationship between trust in sales managers and overall performance of sales personnel. Trust in the sales manager explained the variance in the overall performance; the standardised coefficient of the trust variable was estimated to be (0.4), indicating a very strong association. By the same token, Yang (2005) found empirical evidence supporting the fact that trust in supervisors had a significant and positive impact on task performances; however, the study did not find any support for the relationship between task performance and other trust referents: co-workers and top management.

A meta-analysis by Dirks and Ferrin (2002) noted that positive relationships between trust in the leadership and JP were not supported by their findings. However, their results found a considerable positive association between trust in direct leader and JP $(r=0.17)$. Their study revealed that trust in the supervisor has unique strength over and above the trust in leadership in four of five workplace outcomes. Colquitt, Scott and LePine (2007), in their meta-analysis of 27 samples amounting to 4,882 observations, 
found that task performance is positively and significantly correlated with trust $(r=0.33)$. Considering the above mixed empirical evidence from a normative point of view that presents interpersonal trust as a lubricant in forming healthy interpersonal relationships, we hypothesise positive associations between trust variables and JP.

H7: Trust in peers is positively associated with job performance.

H8: Trust in supervisor is positively associated with job performance.

H9: Trust in top management is positively associated with job performance.

\subsection{Trust and job satisfaction}

The extent to which individuals are satisfied with their current organisation is the definition of JS in the present study (Sims, 2000). JS as a workplace attitude is highly correlated to JP and it was found to be related to a variety of organisational behaviours and constructs, including job involvement, turnover, absenteeism, and job stress (Macdonald and MacIntyre, 1997). JS as a global workplace attitude and its relationships to trust variables are of interest to the present study. Three distinct trust referents were argued to be linked to JS. Our analysis sought to answer the question of whether these three variables can explain the phenomenon independently. Besides, comparing relative impacts of the trust referents on JS will enable researchers and practitioners to understand to what extent trust in certain organisational members can indeed be more relevant to employee satisfaction.

Helliwell and Huang (2010) examined trust in management, trust in co-workers, life satisfaction, JS, and workplace characteristics, utilising samples obtained from Canadian Equality, Security and Community (ESC) and General Social Survey (GSS). These largescope surveys (1,862 and 9,949 observations, respectively) include cross-sectional and cross-national components that aim to answer demographic, behavioural and attitudinal questions, as well as investigate the changing trends over time. JS in the ESC sample was significantly explained by the trust in management variable, whereas in the GSS sample, JS was significantly (but less strongly) predicted by trust in co-workers. Helliwell and Wang (2011) elaborated, from a cross-cultural perspective, on the relationship between trust and wellbeing, and they supported the link with empirical evidence showing that these two constructs are highly correlated. Their evidence supported the argument that directionality is from trust to subjective well-being.

In two healthcare facilities, it was found empirically that the JS of employees was driven by interpersonal trust (Yang, 2005). Trust variables with different referents were found to have a unique and positive impact on JS. Therefore, it was shown that employees are capable of distinguishing the trust referents and attributing each referent with a distinct perception. In line with these findings, Tan and Tan's (2000) results suggested that satisfaction with supervisors is associated with the level of trust in supervisors. Based on the arguments above, we hypothesise that:

H10: Trust in peers is positively associated with job satisfaction.

H11: Trust in supervisors is positively associated with job satisfaction.

H12: Trust in top management is positively associated with job satisfaction.

Table 1 includes all of the hypotheses stated above. 
Table 1 List of hypothesis

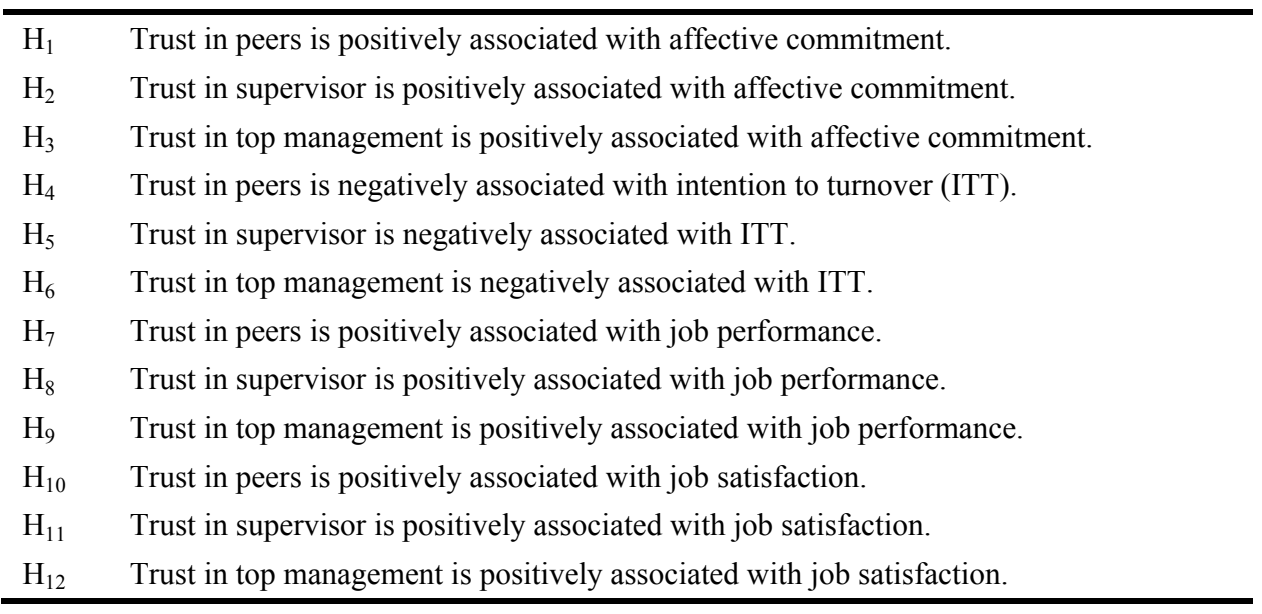

\section{Methodology}

\subsection{Measurement tools}

The present study employed the trust scale from the study by Schoorman, Mayer and Davis (1996). This measurement of trust entails the vulnerability of the truster to the actions of the trustee because of the interdependence and presence of exchanges among individuals in an organisation. This measurement scale consists of four items. Two of the items are reverse-scored. These four statements tap into trust conceptualisation as a whole from various points of views, forming a reflective latent variable. The respondents were asked to check a score for each statement from 1 (strongly disagree) to 5 (strongly agree) that most closely describes their opinion of each item. The following is given as a sample item from this trust scale: I would be comfortable giving my supervisor a task or problem which was critical to me, even if I could not monitor their actions. The items of this scale were repeated in the questionnaire for three different objects: peers, supervisors, and top management. Each trust object was examined in and of itself separately pertaining to the outcome variables. This particular item in trust scale could very well be modified to align with the nature of the relationship between the respondents and their top management. However, observing that this very particular scale proved to be reliable in different workplace settings in a large number of studies showing its discriminant validity (Mayer and Davis, 1999; Schoorman, Mayer and Davis, 2007), we chose to keep the original scale for three objects, letting the data show the consistency of the measurement model. Prior literature also supported the internal consistency of this scale and reported Cronbach's alpha is 0.82 (Schoorman, Mayer and Davis, 1996). Schoorman, Mayer and Davis (2007) noted that even though some studies reported moderately low reliabilities, it was proved to be useful in a variety of contexts, and therefore, ... its conceptual clarity, test-retest reliability, and relationship with other variables in the nomological net (p.348) leverage and support the embracement of the construct. 
The $A C$ scale is adapted from Meyer and Allen (1997). Each of the statements taps on emotional bond with the organisation and the employees' personal commitment based on the level of their loyalty to the organisation. Hence, it is a reflective latent variable. The scale includes six items. There are three reverse-scored items. Meyer and Allen (1997) remarked in their work that considering the estimates of the scale (more than 40), the reported median Cronbach's alpha for the AC scale is 0.85 .

The ITT scale includes seven items and it is adapted from Mayfield and Mayfield (2007). The ITT scale is under a Creative Commons license. There are three reversescored items in this measurement scale. This scale has a Cronbach's alpha of 0.75 .

The present study employed a self-reported JP measure by asking 10 questions pertaining to the subjects' performances. The scale was developed by Mayfield and Mayfield (2006) and its Cronbach's alpha was reported as 0.93. This scale employs wording of comparisons with other employees in the organisation. In order to have adequate levels of variance in responses, the scale anchors were adjusted. The responses range from 1 (Poor) to 5 (Excellent), as opposed to a symmetric scale (i.e., 1-Very Poor, 2-Poor, 3- Average, 4-Good, 5-Very Good). Therefore, having only one option below the average was assumed to increase the spread (variance) in the JP variable. Thus, it is assumed to raise the accuracy of a self-rating measure that may otherwise inflate the observed scores, creating biased and distorted results.

Macdonald and MacIntyre's (1997) JS scale was adopted for the purposes of our model. The scale was deliberately crafted to address a wide range of occupational groups. This scale consists of 10 items that tap into different aspects of JS, including pay, promotion, and working conditions. Reported Cronbach's alpha of the scale is 0.77 .

\subsection{Control variables}

A number of control variables were employed in the present study, such as gender, marital status, and profit seeking/non-profit organisation as dummy variables; education and number of employees in the organisation were treated as categorical variables (i.e., five categories). Other discrete control variables are income, age, experience, and tenure (in years).

Role ambiguity and job autonomy were included in the present model as social psychological factors that might very well change the nature of relationships among organisational attitudes and behaviours. The definition of role ambiguity is existence or clarity of behavioural requirements, often in terms of inputs from the environment, which would serve to guide behaviour and provide knowledge that the behaviour is appropriate (Rizzo, House and Lirtzman, 1970, p.156). A role ambiguity scale was adopted from Rizzo, House and Lirtzman (1970), with a reported Cronbach's alpha of 0.78. Job autonomy is the degree to which job provides substantial freedom, independence and discretion to the individual in scheduling the work and in determining the procedures to be used in carrying it out (Hackman and Oldham, 1976, p.258). These variables are operationalised as latent variables. The job autonomy scale was adopted from Hackman and Oldham (1980); its reported Cronbach's alpha is 0.78 . For job autonomy and role ambiguity, three and six indicators form latent variables, respectively. These latent variables are reflective in nature. 


\subsection{Data collection and demographic statistics}

All scales were compiled into a questionnaire in English with a sentence clarifying the instructions. The survey was then translated into Turkish by the first author and it was back-translated to English by another bilingual professional. Two raters elaborated on the accuracy and the equivalency of the constructs and statements in two languages. Considering that there are 63 survey items in all of the scales, the rater congruence was more than $90 \%$. Any discrepancies were fixed throughout the discussions, making sure the respondents were asked the equivalent questions in both languages. Data was collected from professionals in two countries; Turkey and the USA. Two versions of each survey - paper and electronic copies - were prepared. The survey's electronic copy was posted on the first author's personal website, as well as another professional's internet domain. Besides, survey links were emailed to a number of professionals working in the USA and Turkey. Data collection took place between January 9, 2012 and February 16, 2012.

Using Hofstede cultural typology (four dimensions out of five), the representativeness of the samples was checked. Items measuring the cultural constructs developed by Hofstede (2001) were included in the research survey and therefore, mean scores of cultural dimensions for the two samples were calculated. Three of four dimensions concurred with Hofstede's scores and thus, no indications of a major bias were found based on the Hofstede dimensions across samples (see Appendix-1 for comparison of Hofstede's original scores of countries).

Demographic statistics and sample characteristics are given in Table 2. Sample sizes in the USA and Turkey were initially recorded as 163 and 140, respectively. Sixteen respondents who provided their location somewhere other than the USA and Turkey were excluded (Canada 7, China 1, Mexico 1, the UK 6, Thailand 1). After deleting another three observations from the US sample, including duplicate items and incomplete surveys, the pooled sample had 284 observations. The Turkey sample included 134 observations, whereas the US sample included 150 observations. Descriptive statistics of the demographic variables are as follows:

Table 2 Sample demographics

\begin{tabular}{lcc}
\hline & US sample & TR sample \\
\hline Average age & 40 & 32 \\
Number of years of experience & 17.3 & 9.8 \\
Number of years of tenure & 6.8 & 5.9 \\
Married & $59 \%$ & $60 \%$ \\
Working with non-profit organisation & $55 \%$ & $43 \%$ \\
High school education & $9 \%$ & $5 \%$ \\
Some college & $7 \%$ & $3 \%$ \\
Bachelor's & $25 \%$ & $33 \%$ \\
Master's degree & $31 \%$ & $33 \%$ \\
Beyond Master's & $28 \%$ & $25 \%$ \\
\hline
\end{tabular}




\subsection{Statistical procedures}

Data analysis was conducted using the partial least square (PLS) (Kock, 2010). The PLS does not require a normality assumption for the variable distributions, as opposed to the co-variance based structural equation modelling (SEM) techniques or regression analyses using the ordinary least squares (OLS) (Farahani et al., 2010; Haenlein and Kaplan, 2004). It is also argued that PLS can produce stable path coefficients and significant $p$-values with samples sizes less than 100 (Kock, 2012b), showing the strength of the method. In the current research, we propose a path analysis model as shown in Figure 1. In the conceptual path model, the inner model (paths across variables of interest) and outer model (construction of latent variables with indicators) are simultaneously estimated using PLS-based SEM, and the results of the inner and outer models are discussed.

Figure 1 The conceptual path model

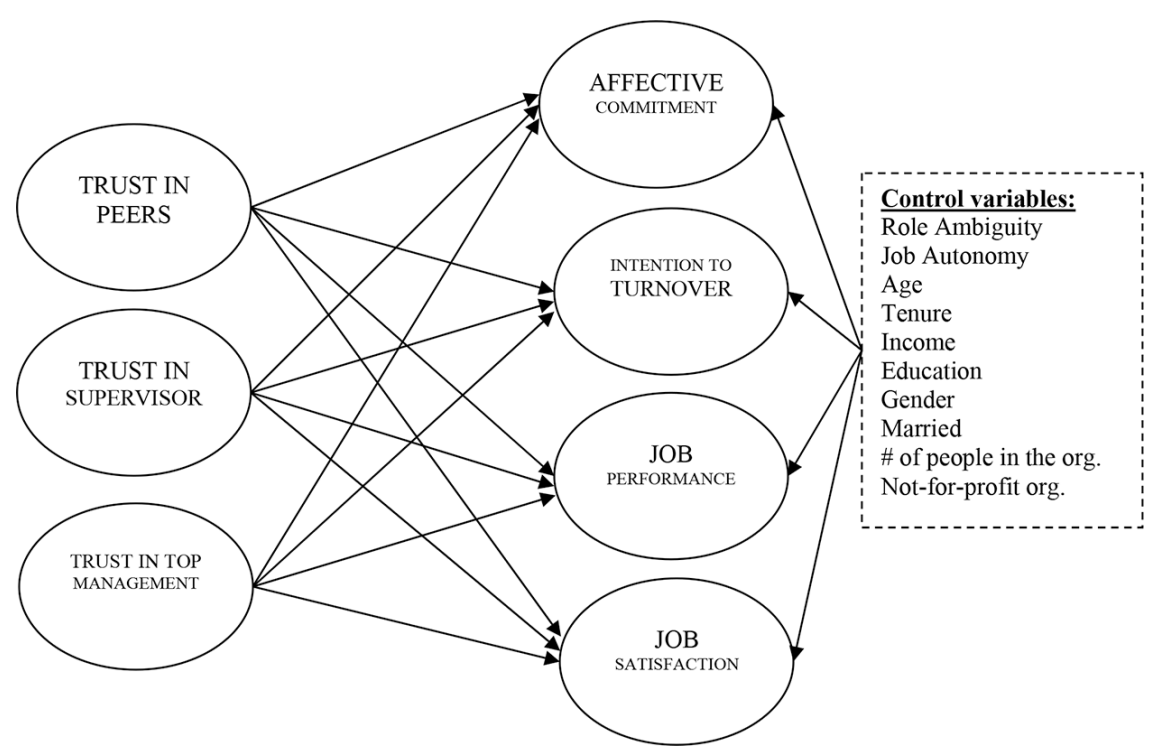

\subsection{Model fit indices and general model elements}

Model fit was assessed by three measures: average path coefficient (APC), average R-squared (ARS), and average variance inflation factor (VIF) (Table 3). As long as the APC and ARS are significant, under the 5\% level, and the third measure is lower than 5, one can conclude that there is a good fit of the model with the data (Kock, 2012b; Rosenthal and Rosnow, 1991). ARS in two samples is not statistically significant, which may be an indication of Simpson's paradox (Kock, 2012b; Wagner, 1982). Such an instance is characterised by the fact that the correlation and path coefficient of a predictor latent variable with respect to a criterion latent variable have the opposite signs. This occurrence implies that those certain paths might be improbable/nonsensical, or that the 
direction of the relationship is reversed (Kock, 2012b). Therefore, these paths in the model reduce the explained variance in the criterion variable.

Table 3 General SEM analysis results

\begin{tabular}{lcc}
\hline & US sample & Turkey sample \\
\hline APC & $0.105, P<0.001$ & $0.120, P<0.001$ \\
ARS & $0.154, P=0.273$ & $0.196, P=0.924$ \\
AVIF & 1.507, Good if $<5$ & 1.573 , Good if $<5$ \\
Algorithm used in the analysis & Warp2 PLS regression & Warp2 PLS regression \\
Resampling method used & Jack-knifing & Jack-knifing \\
$\begin{array}{l}\text { Number of cases (rows) in } \\
\text { data }\end{array}$ & 150 & 134 \\
\hline
\end{tabular}

Compared to the bootstrapping resampling method, the jack-knifing method resulted in more stable coefficients. There was no substantial difference observed with the blindfolding resampling method. Jack-knifing is believed to generate better outcomes for data with outliers and smaller sample sizes (i.e., $n<100$ ) (Kock, 2012b). In the current research, for each indicator there were missing observations (i.e., only several percentages of the sample) and the sample sizes are 150 and 134 for the US sample and the Turkey sample, respectively.

\subsection{Descriptive statistics}

Tables 4 and 5 show the pairwise correlations, means and standard deviations of all the variables used in the current research for the US sample and the Turkey sample, respectively. A mean comparison using a $t$-test was carried out for each of the latent variables. Table 6 shows the mean comparison tests results of the latent variables employed in the SEM model for both of the samples. Comparing the means of two independent samples and using a $t$-test, one should check for the following assumptions: random sampling, populations with normal distribution, and equal variance of two samples (Park, 2009). T-test results may be distorted due to non-normality and skew in the distributions. Therefore, normality tests were conducted for each latent variable. In the US sample, the Shapiro-Wilk test revealed that trust variables (TiP, TiS and TiM) are all normally distributed and test statistics are not statistically significant to reject the normality hypotheses. Similarly, in the Turkey sample, all trust variables were found to have a normal distribution. The variances of two samples for each of the latent variables were contrasted and for those latent variables of equal (TiP, TiM) and unequal variances, separate procedures were adopted for t-tests. Results are shown in Table 6. In the US sample, all of the trust variables (TiP, TiS and TiM) have significantly higher means than the Turkey sample, confirming the cross-cultural study results (i.e., WVS results). 
Table 4 Means, standard deviations and correlations - the US sample

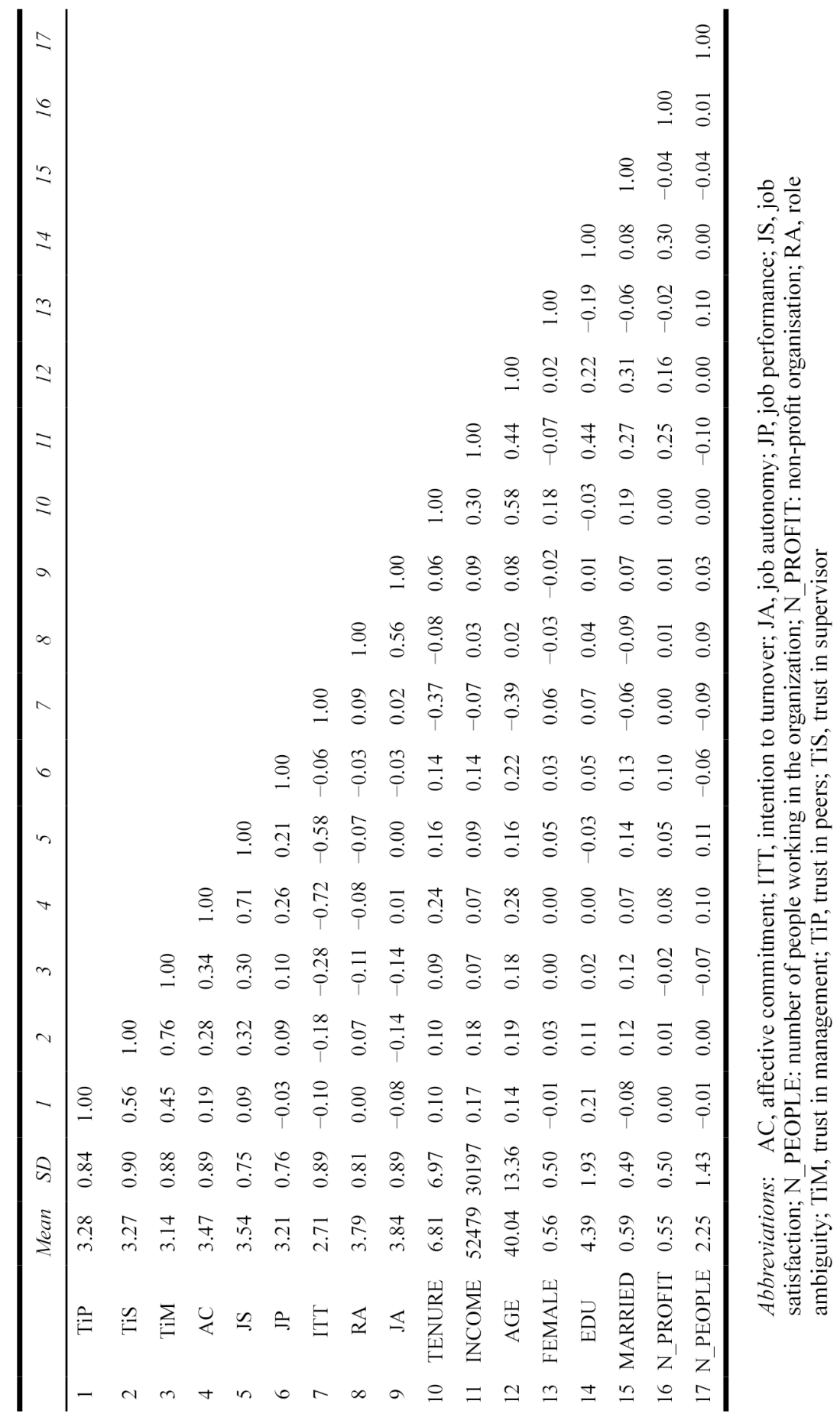


Table 5 Means, standard deviations and correlations - the Turkey sample

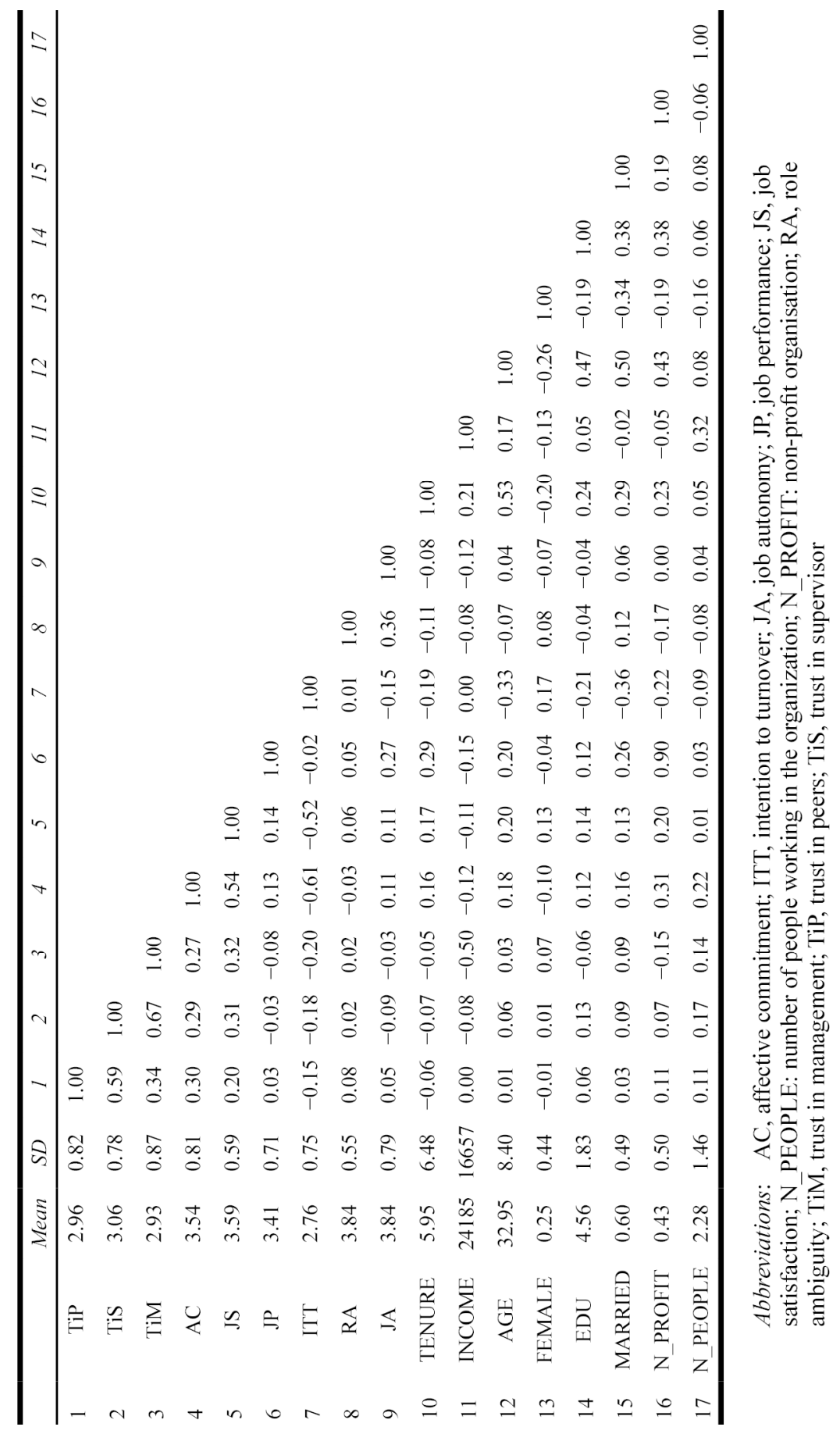


Table 6 Results of the mean comparison tests across samples

\begin{tabular}{lcccccccc}
\hline & \multicolumn{3}{c}{ US sample } & & \multicolumn{3}{c}{ Turkey sample } & \\
\cline { 2 - 4 } Variable & Mean & $S D$ & Normal & & Mean & SD & Normal nnn & p-value \\
\hline TiP & 3.28 & 0.84 & Yes & & 2.98 & 0.82 & Yes & $0.000^{*}$ \\
TiS & 3.27 & 0.9 & Yes & & 3.07 & 0.78 & Yes & $0.020^{* *}$ \\
TiM & 3.14 & 0.88 & Yes & & 2.93 & 0.87 & Yes & $0.017^{* *}$ \\
\hline
\end{tabular}

$* p<0.01$

${ }^{* *} p<0.05 p$-values are from one-tailed tests.

Abbreviations: TiM, trust in management; TiP, trust in peers; TiS, trust in supervisor

\subsection{Measurement model}

A full collinearity check revealed that the collinearity with respect to the TEXP (total experience in years) variable may be problematic. The VIF score of the TEXP variable was found to be just above 7. Therefore, this variable was excluded from the SEM analysis in both samples. In the current study, a confirmatory factor analysis generated latent variable scores as well as loadings of indicators. Loadings are from a structure matrix (i.e., unrotated), and all the loadings are between -1 and +1 (Kock, 2012a). Crossloadings were generated from the pattern matrix (i.e., rotated). To show that the model has acceptable convergent validity, the loadings should be higher than 0.5 and $p$-values associated with the loadings should be lower than 0.05 (Hair, Black, Babin and Anderson, 2009). All of the loadings for two samples except one are higher than 0.5 and significant ( $p$-values $<0.001$ ). Those indicators that did not load higher than 0.5 on the respective latent variable were dropped (Hair et al., 2009; Kline, 1998; Kock, 2012a, 2014).

Discriminant validity of the latent variables is shown using the average variance extracted (AVE) coefficients (Chin, Marcolin and Newsted, 2003). This method is also known as Fornell and Larcker (1981) criterion, and it was found to be widely used in research (Ringle, Sarstedt and Straub, 2012). In Tables 7 and 8, the square roots of the AVE of the latent variables, as well as latent variable correlations are shown for the US sample and the Turkey sample, respectively. Square roots of the AVEs are given on the diagonal. The criterion is that the square roots of the AVE for each latent variable should be higher than any of the correlations of that respective latent variable.

Table 7 Square roots of AVEs and latent variable correlations - the US sample

\begin{tabular}{ccccccccccc}
\hline & & 1 & 2 & 3 & 4 & 5 & 6 & 7 & 8 & 9 \\
\hline 1 & TiP & $(0.788)$ & & & & & & & & \\
2 & TiS & 0.620 & $(0.808)$ & & & & & & & \\
3 & TiM & 0.473 & 0.761 & $(0.776)$ & & & & & \\
4 & AC & 0.212 & 0.290 & 0.337 & $(0.793)$ & & & & & \\
5 & JS & 0.112 & 0.341 & 0.305 & 0.706 & $(0.737)$ & & & \\
6 & JP & -0.029 & 0.075 & 0.113 & 0.248 & 0.200 & $(0.783)$ & & & \\
\hline
\end{tabular}


Table 7 Square roots of AVEs and latent variable correlations - the US sample (continued)

\begin{tabular}{|c|c|c|c|c|c|c|c|c|c|c|}
\hline & & 1 & 2 & 3 & 4 & 5 & 6 & 7 & 8 & 9 \\
\hline 7 & ITT & -0.133 & -0.202 & -0.271 & -0.691 & -0.551 & -0.025 & $(0.772)$ & & \\
\hline 8 & RA & 0.013 & -0.069 & -0.090 & -0.080 & -0.076 & -0.043 & 0.090 & $(0.847)$ & \\
\hline 9 & $\mathrm{JA}$ & -0.051 & -0.133 & -0.108 & 0.018 & -0.011 & -0.031 & 0.031 & 0.570 & $(0.924)$ \\
\hline
\end{tabular}

Abbreviations: AC, affective commitment; ITT, intention to turnover; JA, job autonomy; JP, job performance; JS, job satisfaction; RA, role ambiguity; TiM, trust in management; TiP, trust in peers; TiS, trust in supervisor

Table 8 Square roots of AVEs and latent variable correlations - the Turkey sample

\begin{tabular}{ccccccccccc}
\hline & & 1 & 2 & 3 & 4 & 5 & 6 & 7 & 8 & 9 \\
\hline 1 & TiP & $(0.706)$ & & & & & & & & \\
2 & TiS & 0.565 & $(0.705)$ & & & & & & & \\
3 & TiM & 0.340 & 0.658 & $(0.734)$ & & & & & & \\
4 & AC & 0.280 & 0.277 & 0.285 & $(0.741)$ & & & & & \\
5 & JS & 0.184 & 0.271 & 0.305 & 0.515 & $(0.612)$ & & & & \\
6 & JP & -0.013 & -0.085 & -0.136 & 0.098 & 0.126 & $(0.735)$ & & & \\
7 & ITT & -0.180 & -0.209 & -0.244 & -0.599 & -0.515 & 0.003 & $(0.675)$ & & \\
8 & RA & 0.089 & 0.048 & 0.068 & -0.022 & 0.104 & 0.016 & 0.017 & $(0.625)$ & \\
9 & JA & 0.116 & -0.040 & 0.010 & 0.106 & 0.159 & 0.231 & -0.165 & 0.331 & $(0.866)$ \\
\hline
\end{tabular}

Abbreviations: AC, affective commitment; ITT, intention to turnover; JA, job autonomy; JP, job performance; JS, job satisfaction; RA, role ambiguity; TiM, trust in management; TiP, trust in peers; TiS, trust in supervisor

In the US and the Turkey samples, all of the square roots of AVEs are higher than the correlations of that respective latent variable. This indicates that all the questions in the survey were understood and answered correctly in the way they were meant to be. Respondents directly associated the questions to the underlying latent variables, and therefore, respondents were not confused by answering the questions with respect to other latent variables. With respect to the relatively lower AVEs (i.e., AVE of JB), a discussion by Ping (2005) states that even though AVEs are lower, latent variables with strong reliability coefficients still indicate a good discriminant validity.

In Tables 9 and 10, the R-squared coefficients, composite reliabilities, and VIF scores of each dependent variable were given for the US and Turkey samples, respectively. The $\mathrm{R}$-squared coefficients of the workplace outcomes are between 13 and 34\%. Composite reliability coefficients take indicator loadings into consideration. Composite reliabilities are argued to indicate reliability estimates that are typically higher than Cronbach's alpha, which is due to the downward bias regarding a mathematical issue in the calculation of Cronbach's alpha (Peterson and Kim, 2013). Therefore, we opt to report composite reliabilities only in this study. The generally accepted threshold for composite reliability is 0.7 or higher (Hair et al., 1992; Nunnally and Bernstein, 1994). For both the 
US and Turkey samples, all of the latent variables have composite reliabilities higher than 0.7 .

Table 9 Latent variable coefficients - the US sample

\begin{tabular}{lccccccc}
\hline & $T i P$ & $T i S$ & $T i M$ & $A C$ & $J S$ & $J P$ & ITT \\
\hline R-squared coefficients & 0.10 & 0.11 & 0.11 & 0.20 & 0.18 & 0.13 & 0.21 \\
Composite reliability & 0.76 & 0.78 & 0.75 & 0.92 & 0.87 & 0.93 & 0.91 \\
Full collinearity VIFs & 1.93 & 3.43 & 2.71 & 3.13 & 2.37 & 1.24 & 2.55 \\
\hline
\end{tabular}

Abbreviations: AC, affective commitment; ITT, intention to turnover; JP, job performance; JS, job satisfaction; TiM, trust in management; TiP, trust in peers; TiS, trust in supervisor

Table 10 Latent variable coefficients - the Turkey sample

\begin{tabular}{lccccccc}
\hline & TiP & TiS & TiM & AC & JS & JP & ITT \\
\hline R-squared coefficients & 0.07 & 0.07 & 0.07 & 0.34 & 0.25 & 0.23 & 0.31 \\
Composite reliability & 0.74 & 0.74 & 0.77 & 0.87 & 0.78 & 0.91 & 0.83 \\
Full collinearity VIFs & 1.64 & 2.68 & 2.25 & 2.23 & 1.83 & 1.43 & 2.14 \\
\hline
\end{tabular}

Abbreviations: AC, affective commitment; ITT, intention to turnover; JP, job performance; JS, job satisfaction; TiM, trust in management; TiP, trust in peers;

TiS, trust in supervisor

A full collinearity check was performed and this test was based on the variance inflation factors for each of the latent variables. The traditional and conservative threshold of the VIF scores is 5 or less. From a more relaxed perspective, VIFs should be lower than 10 (Hair et al., 2009). All of the VIFs scores are even lower than the threshold of 5, which is as a cap from the experiences of using PLS for many SEM analyses (Kock, 2012b). Existence of no multicollinearity can be strongly stated for the models.

\section{Results}

See the estimated coefficients on Figure 2 and 3 below. A summary of whether the hypotheses are supported or not is given in Table 11. Support was found for $\mathrm{H}_{1}$ and $\mathrm{H}_{3}$ in both samples. There was no support for $\mathrm{H}_{2}$, whether in the US or the Turkey sample. In both samples, there were no significant associations between trust in supervisors and AC. In two samples, the links between trust in peers and $\mathrm{AC}$ proved to be positive and significant $(\beta=0.16$ under $\% 5$ level, and $\beta=0.13$ under $\% 10$ level in the USA and Turkey samples, respectively). Similarly, the links between trust in top management and $\mathrm{AC}$ were found to be positive and significant under the $5 \%$ level ( $\beta=0.25$ and $\beta=0.28$ in the US and Turkey samples, respectively). 
Figure 2 Estimated path coefficients for the US sample

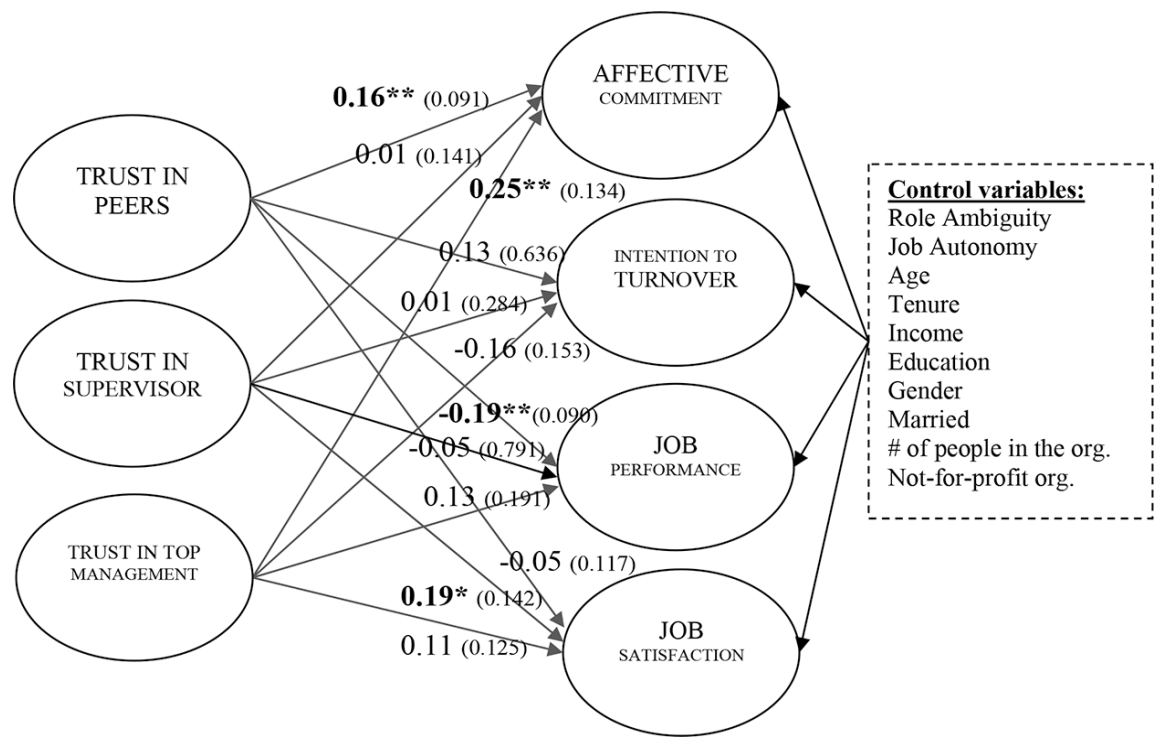

Note: Significance levels are $1 \%(* * *), 5 \%(* *), 10 \%(*)$. Significant path coefficients are in bold. Standard errors are in parentheses.

Figure 3 Estimated path coefficients for the Turkey sample

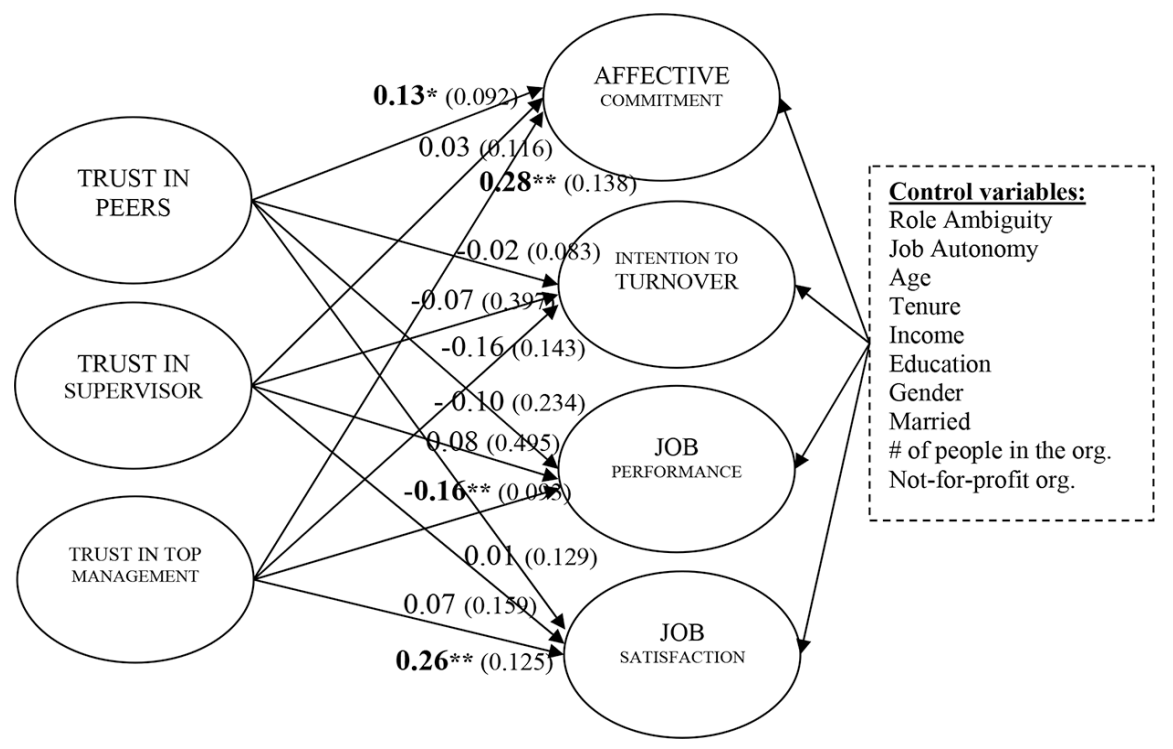

Note: Significance levels are $1 \%(* * *), 5 \%(* *), 10 \%(*)$. Significant path coefficients are in bold. Standard errors are in parentheses. 
Table 11 Summary of the empirical support for the hypotheses

\begin{tabular}{lccl}
\hline$\#$ & TR & US & Hypothesis \\
\hline $\mathrm{H}_{1}$ & Yes & Yes & Trust in peers is positively associated with affective commitment. \\
$\mathrm{H}_{2}$ & No & No & Trust in supervisor is positively associated with affective commitment. \\
$\mathrm{H}_{3}$ & Yes & Yes & Trust in top management is positively associated with affective commitment. \\
$\mathrm{H}_{4}$ & No & No & Trust in peers is negatively associated with intention to turnover (ITT). \\
$\mathrm{H}_{5}$ & No & No & Trust in supervisor is negatively associated with ITT. \\
$\mathrm{H}_{6}$ & No & No & Trust in top management is negatively associated with ITT. \\
$\mathrm{H}_{7}$ & No & No & Trust in peers is positively associated with job performance. \\
$\mathrm{H}_{8}$ & No & No & Trust in supervisor is positively associated with job performance. \\
$\mathrm{H}_{9}$ & No & No & Trust in top management is positively associated with job performance. \\
$\mathrm{H}_{10}$ & No & No & Trust in peers is positively associated with job satisfaction. \\
$\mathrm{H}_{11}$ & No & Yes & Trust in supervisor is positively associated with job satisfaction. \\
$\mathrm{H}_{12}$ & Yes & No & Trust in top management is positively associated with job satisfaction. \\
\hline
\end{tabular}

Rejecting hypotheses $\mathrm{H}_{4}, \mathrm{H}_{5}$ and $\mathrm{H}_{6}$ : there appeared to be no significant association between ITT and the three trust variables. Even though most of the estimated path coefficients of trust variables pointing to ITT were negative, the significance levels are too high to make conclusions. The empirical findings showed that the variance in the ITT variable could not be explained significantly with any of the three trust variables. Therefore, the hypotheses were not supported.

Hypotheses with respect to JP $\left(\mathrm{H}_{7}, \mathrm{H}_{8}\right.$ and $\left.\mathrm{H}_{9}\right)$ were not supported. There are two variables negatively and significantly associated with JP: trust in peers in the US sample and trust in top management in the Turkey sample. The remaining trust variables in the two samples turned out to have no association with respect to JP. In the US sample, the relationship between trust in peers and JP was estimated to be $(\beta=-0.19)$ and significant under 5\%. In the Turkey sample, the relationship between trust in top management and JP was estimated to be $(\beta=-0.15)$ and significant under $5 \%$. These two significant and negative associations did not support the hypotheses.

Hypothesis $\mathrm{H}_{10}$ did not receive support from the empirical results in two samples. In the US sample, trust in supervisors is positively and significantly level associated with JS ( $\beta=0.19$ under $5 \%$ ), supporting $\mathrm{H}_{11}$. On the other hand, in the Turkey sample, trust in top management is positively associated with JS $(\beta=0.26)$ and it is significantly under the $5 \%$ level, supporting $\mathrm{H}_{12}$. See Tables 12 and 13 for estimations of control variables.

We observed that in the US sample (Table 12) role ambiguity, income, marital status, education, and profit/non-profit organisation did not associate with any of the workplace outcome variables. Job autonomy was negatively associated with JP. A higher tenure in terms of the number of years with current organisation results in a lesser ITT. Gender was only associated with ITT and females on average tended to have a higher intention to quit. Similarly, the employees feel more satisfied and have lower ITT if the organisation is on average larger in size. The JP of the employee on average is lower if the organisation is larger. Age was found to increase AC, whereas there is a negative effect on ITT. 
Table 12 PLS path estimations of variables for the US sample

\begin{tabular}{lcccc}
\hline \multicolumn{4}{c}{ Dependent variables } \\
\hline & $\begin{array}{c}\text { Affective } \\
\text { commitment }\end{array}$ & $\begin{array}{c}\text { Intention to } \\
\text { turnover }\end{array}$ & $\begin{array}{c}\text { Job } \\
\text { performance }\end{array}$ & $\begin{array}{c}\text { Job } \\
\text { satisfaction }\end{array}$ \\
\hline Trust in peers & $0.16^{*}$ & 0.13 & $-0.19^{*}$ & -0.05 \\
Trust in supervisor & 0.01 & 0.01 & -0.05 & $0.19^{* *}$ \\
Trust in top management & $0.25^{*}$ & -0.16 & 0.13 & 0.11 \\
Role ambiguity & -0.07 & 0.08 & 0.02 & -0.03 \\
Job autonomy & 0.08 & 0.03 & $-0.10^{* *}$ & 0.02 \\
Age & $0.18^{*}$ & $-0.29^{* * *}$ & 0.12 & 0.06 \\
Tenure & 0.08 & $-0.17^{*}$ & 0.01 & 0.06 \\
Income & 0.07 & -0.04 & 0.07 & -0.03 \\
Education & 0.05 & 0.13 & 0.01 & -0.01 \\
Female & -0.04 & $0.17^{*}$ & 0.07 & 0.04 \\
Married & 0.02 & 0.08 & 0.10 & 0.12 \\
Number of people in the org. & $0.15^{*}$ & $-0.15^{*}$ & $-0.11^{* *}$ & $0.16^{*}$ \\
Not-for-profit org. & 0.11 & 0.02 & 0.08 & 0.07 \\
\hline
\end{tabular}

Note: Significance levels are marked with *, **, *** $10 \%, 5 \%, 1 \%$, respectively.

For the Turkey sample (Table 13), role ambiguity was found to increase ITT and JS. The higher the job autonomy, the higher is the JS and the lower the ITT. Tenure is positively associated with AC, JP and JS. Income is negatively associated with AC and JP. Employees on average tend to have stronger affective ties to their organisation if the organisation is larger. Being married lowers ITT. Working with a non-profit organisation entails higher $\mathrm{AC}$ and lower performance. Gender, education, and age did not associate with any of the workplace outcomes significantly.

Table 13 PLS path estimations of variables for the Turkey sample

\begin{tabular}{lcccc}
\hline & \multicolumn{4}{c}{ Dependent variables } \\
\hline Trust in peers & $\begin{array}{c}\text { Affective } \\
\text { commitment }\end{array}$ & $\begin{array}{c}\text { Intention to } \\
\text { turnover }\end{array}$ & $\begin{array}{c}\text { Job } \\
\text { performance }\end{array}$ & $\begin{array}{c}\text { Job } \\
\text { satisfaction }\end{array}$ \\
\hline Trust in supervisor & $0.13^{*}$ & -0.02 & -0.10 & 0.01 \\
Trust in management & 0.03 & -0.07 & 0.08 & 0.07 \\
Role ambiguity & $0.28^{* *}$ & -0.16 & $-0.16^{* *}$ & $0.26^{* *}$ \\
Job autonomy & -0.08 & $0.12^{*}$ & -0.03 & $0.19^{* * *}$ \\
Age & 0.09 & $-0.16^{* *}$ & 0.16 & $0.13^{*}$ \\
Tenure & 0.01 & -0.15 & -0.01 & 0.01 \\
Income & $0.18^{*}$ & -0.07 & $0.31^{* * *}$ & $0.20^{* *}$ \\
Education & $-0.20^{* *}$ & 0.09 & $-0.28^{* *}$ & -0.09 \\
\hline
\end{tabular}


Table 13 PLS path estimations of variables for the Turkey sample (continued)

\begin{tabular}{lcccc}
\hline & \multicolumn{4}{c}{ Dependent variables } \\
\hline & $\begin{array}{c}\text { Affective } \\
\text { commitment }\end{array}$ & $\begin{array}{c}\text { Intention to } \\
\text { turnover }\end{array}$ & $\begin{array}{c}\text { Job } \\
\text { performance }\end{array}$ & $\begin{array}{c}\text { Job } \\
\text { satisfaction }\end{array}$ \\
\hline Female & -0.07 & 0.07 & 0.12 & 0.12 \\
Married & -0.01 & $-0.17 * *$ & 0.10 & -0.01 \\
Number of people in the org. & $0.21 * * *$ & -0.13 & 0.06 & -0.12 \\
Not-for-profit org. & $0.23 * *$ & -0.06 & -0.03 & $0.13^{*}$ \\
\hline
\end{tabular}

Note: Significance levels are marked with *, **, *** 10\%, 5\%, 1\%, respectively.

The current research found that the larger the organisation, the higher the AC. This relationship holds in two samples. It may be due to the fact that in larger organisations, there are well established rules and regulations, formalisations, well-defined operations, duties, and work designs. It could also be argued that the organisational culture in larger organisations may create a sense of belonging and attachment, hence driving organisational commitment. The corollary to the existence of a strong organisational culture is that the employees are emotionally related to the organisation and want to continue working with it. Another possible explanation departs from the discussion of Meyer and Allen (1997) on the broader 'roles' that require a greater variety of skills and ability to adapt to the demands of situation (p.5). In larger organisations, job complexity might increase the job requirements for an employee and therefore, the organisation commits more resources to this particular employee (i.e., training). From a reciprocity perspective, the employee in response feels more attached and committed to the organisation.

\subsection{Path coefficient comparisons}

To also highlight the different results of two samples, we investigate the significant differences of path coefficients generated by the analysis of two samples. Rather than including an interaction term in our model, an analogous method of comparing path coefficients of the two samples was employed, using standard errors of path coefficients and sample sizes. Thus, discussion of the differences in the two samples could be made in a robust way. Multi-group data analysis could reveal the changing patterns across groups or samples (Kock, 2014). Table 14 shows the comparisons of the path coefficients of two samples. T-tests were employed to test for the multi-group difference effect when the research includes two or more samples that are generally collected in multiple countries ${ }^{3}$. The results suggest that there are no differences, except one marginally significant difference across samples regarding the estimated path coefficients from 'trust in management' to 'job performance'. Therefore, the findings reveal that the conceptual model is mostly equivalent across the samples, and paths are similarly meaningful in the two samples. 
Table 14 Results of path coefficient comparison tests

\begin{tabular}{|c|c|c|c|c|c|}
\hline \multirow[b]{2}{*}{ Path } & \multicolumn{2}{|c|}{ US sample } & \multicolumn{2}{|c|}{ Turkey sample } & \multirow[b]{2}{*}{$p$-value } \\
\hline & $\beta$ & $S E$ & $\beta$ & $S E$ & \\
\hline $\mathrm{TiP} \rightarrow \mathrm{AC}$ & $0.16^{*}$ & 0.091 & $0.13 * *$ & 0.092 & $0.39 \mathrm{NS}$ \\
\hline $\mathrm{TiP} \rightarrow \mathrm{ITT}$ & 0.13 & 0.636 & -0.02 & 0.083 & $0.41 \mathrm{NS}$ \\
\hline $\mathrm{TiP} \rightarrow \mathrm{JP}$ & -0.19 & 0.090 & -0.10 & 0.234 & $0.35 \mathrm{NS}$ \\
\hline $\mathrm{TiP} \rightarrow \mathrm{JS}$ & -0.05 & 0.117 & 0.01 & 0.129 & $0.36 \mathrm{NS}$ \\
\hline $\mathrm{TiS} \rightarrow \mathrm{AC}$ & 0.01 & 0.141 & 0.03 & 0.116 & $0.45 \mathrm{NS}$ \\
\hline $\mathrm{TiS} \rightarrow \mathrm{ITT}$ & 0.01 & 0.284 & -0.07 & 0.397 & $0.43 \mathrm{NS}$ \\
\hline $\mathrm{TiS} \rightarrow \mathrm{JP}$ & -0.05 & 0.791 & 0.08 & 0.495 & $0.44 \mathrm{NS}$ \\
\hline $\mathrm{TiS} \rightarrow \mathrm{JS}$ & $0.19^{*}$ & 0.142 & 0.07 & 0.159 & $0.28 \mathrm{NS}$ \\
\hline $\mathrm{TiM} \rightarrow \mathrm{AC}$ & $0.25^{*}$ & 0.134 & $0.28^{*}$ & 0.138 & $0.44 \mathrm{NS}$ \\
\hline $\mathrm{TiM} \rightarrow \mathrm{ITT}$ & -0.16 & 0.153 & -0.16 & 0.143 & $0.50 \mathrm{NS}$ \\
\hline $\mathrm{TiM} \rightarrow \mathrm{JP}$ & 0.13 & 0.191 & $-0.16^{*}$ & 0.093 & $0.09 * *$ \\
\hline $\mathrm{TiM} \rightarrow \mathrm{JS}$ & 0.11 & 0.125 & $0.26^{*}$ & 0.125 & $0.19 \mathrm{NS}$ \\
\hline
\end{tabular}

Abbreviations: AC, affective commitment; ITT, intention to turnover; JP, job performance; JS, job satisfaction; TiM, trust in management; TiP, trust in peers; TiS, trust in supervisor

Significance levels are marked with *,** $10 \%, 5 \%$ respectively

\section{Discussion and conclusion}

Empirical support for some of the hypotheses in the current research suggests that the level of trust with respect to organisational members plays a role in explaining global workplace outcomes. Trust is an essential part of the social relationships and its normative point of view was partially acknowledged with the findings of this research. Trust among employees as one of the prominent factors in highly interdependent organisational environment may function as grease increasing social exchanges and effectiveness in general. The current research is consistent with the results of crosscultural studies of generalised trust in that the higher levels of trust constructs were observed in the US sample (Morrone, Tontoranelli and Ranuzzi, 2009).

The findings suggest particular patterns of relationships. Associations that have similar nature in the two samples are with respect to AC, whereas those that differed across the two samples are with respect to JP and JS. AC is predicted positively by the existence of trust in peers and trust in top management in both of the samples. The current research empirically concludes and confirms to the extant literature (i.e., Ferres, Connell and Travaglione, 2004; Kaneshiro, 2008; de Ruyter, Moorman and Lemmink, 2001; Yang, 2005) in that trust in peers and trust in top management have significantly predicted AC. However, in both samples, trust in supervisors did not significantly associate with AC.

The relation between top management and employees in terms of the employment contract perspective creates economic exchange. On the other hand, top management's treatment of employees (i.e., emphasising the importance of the associates, involvement, 
empowerment and participation of employees) can be considered as social exchange (Blau, 1964), which functions as the underlying mechanism that forms trust. Thereby, organisational members embark on higher AC.

Fostering trust in peers may function as a social catalyst that improves individual and organisational effectiveness (Ferres, Connell and Travaglione, 2004). Our empirical findings suggest that levels of trust in peers can play a role in bringing about AC. To observe reasonable AC levels for professionals and managers in organisational settings, it is very important to form good, healthy and trusting relationships among co-workers.

This study proposed that the three trust referents have distinct and negative impacts on ITT. Neither of the samples generated any significant relationships between trust variables and ITT, not confirming the prior literature (Davis et al., 2000; Ferres, Connell and Travaglione, 2004; Luis, 1995; Tan and Tan, 2000). What the current study adds is that ITT arguably is determined by mostly the contractual relationship between the employee and the organisation. It can be said that this type of relationship is considered to be economic exchange, as opposed to social exchange (Blau, 1964). Therefore, considering an employee - organisation relationship that is characterised by economic terms and benefits, ITT may not be a function of the actual trust in organisational members because trust is characterised by a process of give and take behaviour among organisational members. Instead, ITT may be explained as a function of economic exchange.

In the current research, a negative association has been found between two trust variables and JP. These results are seemingly counter intuitive. The extant literature suggests a reasonably positive association; however, this positive link between trust and individual performance has not been fully established by the accumulation of empirical research (Yang, 2005). Costigan, Ilter and Berman (1998) reported that there was a positive association between affective trust in co-workers and motivation that may eventually lead to enhanced individual performance. A research study by Dirks (1999) suggested that trust in teammates functions as a moderator of motivation rather than having a direct effect, and thereby influencing team performance. One can argue that trust functions as a moderator from a contextual perspective with respect to motivation and performance, rather than having direct effects on individual workplace outcomes.

Team effect may provide insights about understanding this negative association. Langfred (2004) found that team performance may suffer due to high level of trust when combined with low monitoring of team members. In the current research, the explanation of a negative impact of trust in peers, including co-workers and colleagues at the same level of authority in the organisation, could be reasonably based on the assumption that the individuals are heavily interdependent with their peers, forming teams. Assuming the interdependency translates into the existence of work teams, the high level of trust in peers and team members can be associated with relaxed control, and therefore, lower individual performance. Besides, examining this link as a negative relationship may be insightful in a deductive sense that the individual does not trust peers because they may not be trustworthy at all. Therefore, to avoid the vulnerability of the dependency on these unreliable peers, the individual exerts extra efforts to make up for the differential outcome that would otherwise be provided by the peers. A recent research on team trust by Mach, Dolan and Tzafrir (2010) reported that among professional elite athletes, trust between team members indirectly impacted team performance through the mediation of team cohesion. Such findings support the notion that trust in peers and team members do 
affect outcomes, including performance, although this happens via moderation or mediation of other dynamics.

In the Turkey sample, the risk of termination of employment as a motivational stimulus may play a role, implying a negative relationship between trust in top management and individual performance. As the employee perceives or observes that top management is not trustworthy and lacks integrity; the person's psychological state towards leadership might involve a low level of trust. The employee's behavioural response to low trust in the leadership of the organisation translates to higher performance in the sense that the individual tries to secure his or her job position by showing higher performance, engaging more effectively and efficiently with respect to job duties compared to his/her colleagues. This argument is consistent with the higher uncertainty avoidance in Turkey compared to the USA. No significant association between the aforementioned variables in the US sample supports our point of view. High uncertainty avoidance connotes that people tend to minimise the unknown, anxiety, and tension (Hofstede, 2001). Therefore, respondents in Turkey are willing to stay with their organisations by working even harder, even though they do not trust top management, thereby securing their job positions. This would protect the individuals from facing the uncertainty associated with unemployment and job seeking. The two digit unemployment rates $(10.2 \%)$ in Turkey announced by the Turkish Statistical Institute by the time this research survey actually took place (January, 2012) further the interpretation of such negative association.

The study has found that trust in supervisors in the US sample promotes the satisfaction of the employee with the job, whereas in the Turkey sample, trust in top management increases JS. In neither of the samples does trust in peers significantly associate with employee JS. The findings suggest that the level of trust in supervisors is an essential factor in an employee feeling happy about his/her job. Confirming prior studies, the current research concluded that trust in different referents might have the main effects on JS. In the same vein, Rich's (1997) findings suggested that trust in manager mediates the relationship between JS and the manager's role modelling. Yang (2005) noted that due to the increased vulnerability of an employee in relation to the higher authorities in the organisation (i.e., termination of employment), trust in organisational members with higher levels of authority could enhance the satisfaction of the employee. On the other hand, JS was leveraged by only trust in supervisors in the US sample, which is consistent with the fact that global workplace outcomes are more closely associated with trust in direct supervisors than trust in leadership (Nyhan, 1999; Dirks and Ferrin, 2002).

\subsection{Practical implications}

This research, using data from Turkey and the USA, empirically examined the associations between the trust variables and workplace outcomes, which were found to be a function of three trust referents (peers, supervisors and top management) with varying effects. Our research, having an international dimension, raises the question of whether cultural differences do matter in explaining the functions of interpersonal trust in organisations.

Our findings suggest that in organisations, if there is a low level of AC among employees, managers should highlight and investigate the relationships among same-line employees. In particular, the increasing interaction among employees at the same level 
leading to trust formation could be addressed to stimulate employees' organisational commitment. Because the social exchange is based on the norm of reciprocity, as the individuals engage in quality give-and-take behaviours, the individuals develop higher trust towards peers over time as well as commitment to one another (Cropanzano and Mitchell, 2005). Strong bonds among peers translate into the identification of employees with the organisation and individuals tend to a have higher sense of belonging and involvement.

Considering the importance of trust in top management that the current research holds, we can argue that the frequency of interaction between top management and employees can stimulate the social exchanges among employees and the management. The perception of the employees about the top management can be advanced by expressing and showing more value, respect towards employees and allowing employees to engage with their superiors and senior management (Meyer and Allen, 1997). Therefore, employees can form better perceptions of trustworthiness, benevolence and fairness about the management of the organisation. This might very well influence overall effectiveness of the individuals in the organisation.

The nature of the trust in supervisors poses that the relationship is between two individuals as opposed to a relationship between an individual and a group. Getting along with the supervisor is assumed to be associated with JS (Macdonald and MacIntyre, 1997). Such social relationships could involve the fact that each party fulfils the expectations and unidentified obligations (Blau, 1964) forming the basis of confidence and reliance. Therefore, for managers and supervisors, it is important to convey integrity, accountability and transparency to the subordinates to build trust, which would have an impact on the organisational behaviour of employees.

\subsection{Limitations and future research}

One of the limitations of the current research related to the nature of the relationships between trust variables and workplace outcomes. This research proposes that there are direct effects of the actual level of trust on the selected attitudinal and performance outcomes. However, having no relationship at all with respect to ITT and having two negative links between trust variables and JP might suggest that the direct or main effect of the trust variables might not be the case. Therefore, it would be enlightening to expand the research, examining the moderating role of interpersonal trust among organisational behaviours and workplace outcomes (Dirks, 1999).

Other limitations relate to the concerns raised about the validity of the subjective selfreported data, common method and common source bias (Meyer, 1980; Thornton, 1980; Vandenabeele, 2009). Besides, future studies can enrich the understanding of the role of trust in organisations by examining the phenomenon longitudinally and taking the time factor into consideration. Because the nature of work relationships in an organisation can alter dramatically over time (Mayer, Davis and Schoorman, 1995), it would require a careful analysis of the trust situation to control for the variables that could change the power of the associations, and even the sign of the relationship (Johns, 2006). 


\section{References}

Afzal, M. and Afzal, U. (2014) 'Effect of knowledge management practices and the moderating role of interpersonal trust on firm's performance: a study in software industry of Pakistan', African Journal of Business Management, Vol. 8, No. 19, pp.864-872.

Allen, N.J and Meyer, J.P. (1996) 'Affective, continuance, and normative commitment to the organization: an examination of construct validity', Journal of Vocational Behavior, Vol. 49, No. 3, pp.252-276.

Balkan, M.O., Serin, A.E and Soran, S. (2014) 'The relationship between trust, turnover intentions and emotions: an application', European Scientific Journal, Vol. 10, No. 2, pp.73-85.

Bateman, T. and Strasser, S. (1984) 'A longitudinal analysis of the antecedents of organizational commitment', Academy of Management Journal, Vol. 27, No. 1, pp.95-112.

Blau, P.M. (1964) Exchange and Power in Social Life, John Wiley, New York, NY.

Cascio, W.F. (1995) 'Whither industrial and organizational psychology in a changing world of work?' American Psychologist, Vol. 50, No. 11, pp.928-939.

Chin, W.W., Marcolin, B.L and Newsted, P.R. (2003) 'A partial least squares latent variable modeling approach for measuring interaction effects: results from a Monte Carlo simulation study and an electronic-mail emotion/adoption study', Information Systems Research, Vol. 14, No. 2, pp.189-218.

Colquitt, J.A., Scott, B.A. and LePine, J.A. (2007) 'Trust, trustworthiness, and trust propensity: A meta-analytic test of their unique relationships with risk taking and job performance', Journal of Applied Psychology, Vol. 92, No. 4, pp.909-927.

Costigan, R.D., Ilter, S.S and Berman, J.J. (1998) 'A multi-dimensional study of trust in organizations', Journal of Managerial Issues, Vol. 10, No. 3, pp.303-317.

Cropanzano, R. and Mitchell, M. (2005) 'Social exchange theory: an interdisciplinary review', Journal of Management, Vol. 31, No. 6, pp.874-900.

Davis, J.H., Schoorman, F.D., Mayer, R.C. and Tan, H.H. (2000) 'Trusted general manager and business unit performance: empirical evidence of a competitive advantage', Strategic Management Journal, Vol. 21, No. 5, pp.563-576.

de Ruyter, K., Moorman, L. and Lemmink, J. (2001) 'Antecedents of commitment and trust in customer-supplier relationships in high technology markets', Industrial Marketing Management, Vol. 30, No. 3, pp.271-286.

Dirks, K.T. (1999) 'The effects of interpersonal trust on work group performance', Journal of Applied Psychology, Vol. 84, No. 3, pp.445-455.

Dirks, K.T. and Ferrin, D.L. (2002) 'Trust in leadership: meta-analytic findings and implications for research and practice', Journal of Applied Psychology, Vol. 87, No. 4, pp.611-628.

Erikson, E.H. (1953) 'Growth and cases of the "healthy personality"', in C. Kluckhohn and H. Murray (Eds): Personality in Nature, Society, and Culture, 2nd ed., Knopf, New York, NY.

Erikson, E.H. (1963) Childhood and Society, 2nd ed., Norton, New York, NY.

Farahani, H.A., Rahiminezhad, A., Same, L. and Immannezhad, K. (2010) 'A Comparison of partial least squares (PLS) and ordinary least squares (OLS) regressions in predicting of couples mental health', Procedia Social and Behavioral Sciences, Vol. 5, pp.1459-1463.

Ferres, N., Connell, J and Travaglione, A. (2004) 'Co-worker trust as a social catalyst for constructive employee attitudes', Journal of Managerial Psychology, Vol. 19, No. 6, pp.608-622.

Festinger, L. (1957) A Theory of Cognitive Dissonance, Stanford University Press, Stanford, CA.

Fornell, C. and Larcker, D.F. (1981) 'Evaluating structural equation models with unobservable variables and measurement error', Journal of Marketing Research, Vol. 18, No. 1, pp.39-50.

Glissmeyer, M. (2010) An Extension of Trust Theory: Opportunism as a Proxy for Distrust? An Examination of a Multivariate Relationship within the Banking Industry', (Doctoral dissertation). Retrieved from ProQuest Dissertations and Theses. 
Guinot, J., Chiva, R and Roca-Puig, V. (2014) 'Interpersonal trust, stress and satisfaction at work: an empirical study', Personnel Review, Vol. 43, No. 1, pp.96-115.

Hackman, J.R. and Oldham, G.R. (1976) 'Motivation through the design of work: test of a theory', Organizational Behavior and Human Performance, Vol. 16, No. 2, pp.250-279.

Hackman, J.R. and Oldham, G.R. (1980) Work Redesign, Addison Wesley, Reading, MA.

Haenlein, M. and Kaplan, A.M. (2004) 'A beginner's guide to partial least squares analysis', Understanding Statistics, Vol. 3, No. 4, pp.283-297.

Hair, J.F., Anderson, R.E., Tatham, R.L. and Black, W.C. (1992) Multivariate Data Analysis with Readings, MacMillan, New York, NY.

Hair, J.F., Black, W.C., Babin, B.J and Anderson, R.E. (2009) Multivariate Data Analysis, Prentice Hall, Upper Saddle River, NJ.

Hausman, A and Johnston, W.J. (2010) 'The impact of coercive and non-coercive forms of influence on trust, commitment, and compliance in supply chains', Industrial Marketing Management, Vol. 39, 519-526.

Heider, F. (1958) The Psychology of Interpersonal Relations, Wiley, New York, NY.

Hofstede, G. (2001) Culture's Consequences: Comparing Values, Behaviors, Institutions, and Organizations Across Nations, 2nd ed., Sage Publications, Inc, Thousand Oaks, CA.

Jiang, Z., Gollan, P.J and Brooks, G. (2015) 'Moderation of doing and mastery orientations in relationships among justice, commitment, and trust', Cross Cultural Management, Vol. 22, No. 1, pp.42-67.

John, F., Helliwell \& Haifang Huang (2010) 'How's the Job? Well-Being and Social Capital in the Workplace', Industrial and Labor Relations Review, Vol. 63, No. 2, pp.205-227.

John F., Helliwell \& Shun Wang (2011) 'Weekends and Subjective Well-Being', NBER Working Papers 17180, National Bureau of Economic Research, Inc.

Johns, G. (2006) 'The essential impact of context on organizational behavior', Academy of Management Review, Vol. 31, No. 2, pp.396-408.

Kaneshiro, P. (2008) Analyzing the Organizational Justice, Trust and Commitment Relationship in a Public Organization, PhD Thesis, North Central University.

Kline, R.B. (1998) Principles and Practice of Structural Equation Modeling, The Guilford Press, New York, NY.

Kock, N. (2010) 'Using WarpPLS in e-collaboration studies: an overview of five main analysis steps', International Journal of e-Collaboration, Vol. 6, No. 4, pp.1-11.

Kock, N. (2012a), 'Lateral collinearity and misleading results in variance-based SEM: an illustration and recommendations', Journal of the Association for Information Systems, Vol. 13, No. 7, pp.546-580.

Kock, N. (2012b), 'WarpPLS 3.0 User Manual', ScriptWarp Systems, Laredo, TX.

Kock, N. (2014) 'Advanced mediating effects tests, multi-group analyses, and measurement model assessments in PLS-based SEM', International Journal of e-Collaboration, Vol. 10, No. 1, pp.1-13.

Langfred, C.W. (2004) 'Too much of a good thing? Negative effects of high trust and individual autonomy in self-managing teams', The Academy of Management Journal, Vol. 47, No. 3, pp.385-399.

Luhmann, N. (1979) Trust and Power, John Wiley \& Sons, New York.

Luis, P. (1995) 'Trust in management and job satisfaction as predictors of turnover intention', (Doctoral dissertation). Retrieved from ProQuest Dissertations and Theses.

Macdonald, S. and MacIntyre, P. (1997) 'The generic job satisfaction scale: scale development and its correlates', Employee Assistance Quarterly, Vol. 13, No. 2, pp.1-16.

Mach, M., Dolan, S. and Tzafrir, S. (2010) 'The differential effect of team members' trust on team performance: the mediation role of team cohesion', Journal of Occupational and Organizational Psychology, Vol. 83, No. 3, pp.771-794. 
Mathieu, J.E. and Zajac, D.M. (1990) 'A review and meta-analysis of the antecedents, correlates and consequences of organisational commitment', Psychological Bulletin, Vol. 108, No. 2, pp.171-194.

Mayfield, J and Mayfield, M. (2006) 'The benefits of leader communication on part-time worker outcomes: a comparison between part-time and full-time employees using motivating language', Journal of Business Strategies, Vol. 23, No. 2, pp.131-153.

Mayfield, J and Mayfield, M. (2007) 'The creative environment's influence on intent to turnover: a structural equation model and analysis', Management Research News, Vol. 31, No. 1, pp.41-56.

Mayer, R.C. and Davis, J.H. (1999) 'The effect of the performance appraisal system on trust for management: a field quasi-experiment', Journal of Applied Psychology, Vol. 84, No. 1, pp.123-136.

Mayer, R.C., Davis, J.H. and Schoorman, F.D. (1995) 'An integrative model of organizational trust', Academy of Management Review, Vol. 20, No. 3, pp.709-734.

McAllister, D.J. (1995) 'Affect- and cognition-based trust as foundations for interpersonal cooperation in organizations', Academy of Management Journal, Vol. 38, No. 1, pp.24-59.

Meyer, H.H. (1980) 'Self-appraisals of job performance', Personnel Psychology, Vol. 33, No. 2, pp.291-295.

Meyer, J.P. and Allen, N.J. (1997) Commitment in the Workplace: Theory, Research and Applications', Sage, Thousand Oaks, CA.

Michaelis, B., Stegmaier, R. and Sonntag, K. (2009) 'Affective commitment to change and innovation implementation behavior: the role of charismatic leadership and employees' trust in top management', Journal of Change Management, Vol. 9, No. 4, pp.399-417.

Morrone, A., Tontoranelli, N. and Ranuzzi, G. (2009) 'How good is trust? Measuring trust and its role for the progress of societies', OECD Statistics Working Papers, OECD Publishing.

Nyhan, R.C. (1999) 'Increasing affective organizational commitment in public organizations: the key role of interpersonal trust', Review of Public Personnel Administration, Vol. 19, No. 3, pp.58-70.

Nunnally, J.C. and Bernstein, I.H. (1994) Psychometric theory, McGraw-Hill, New York, NY.

Paliszkiewicz, J., Koohang, A and Nord, J.H. (2014) 'Management trust, organizational trust, and organizational performance: Empirical validation of an instrument', Online Journal of Applied Knowledge Management, Vol. 2, No. 1, pp.28-39.

Park, H.M. (2009) Comparing Group Means: T-tests and One-way ANOVA using STATA, SAS, R, and SPSS', Working Paper. The University Information Technology Services (UITS) Center for Statistical and Mathematical Computing, Indiana University." http://www.indiana.edu/ $\sim$ statmath/stat/all/ttest

Peterson, R.A. and Kim, Y. (2013) 'On the relationship between coefficient alpha and composite reliability', Journal of Applied Psychology, Vol. 98, No. 1, pp.194-198.

Ping, R.A. (2005) 'What is the "validity" of a latent variable interaction (or quadratic)?' Available from: http://home.att.net/ rpingjr/validity.doc

Powell, M. and Ferguson, Y. (2014) A Cross Cultural Study of Employee Attitudes to Trust in Management in Ghana and the UK', Working Paper, University Forum for Human Resource Development, http://www.ufhrd.co.uk.

Putnam, R.D. (1993) Bowling Alone, Simon \& Schuster Paperbacks, New York.

Reeskens, T. and Hooghe, M. (2008) 'Cross-cultural measurement equivalence of generalized trust: evidence from the European Social Survey (2002 and 2004)', Social Indicators Research, Vol. 85, No. 3, pp.515-532.

Rich, G.A. (1997) 'The sales manager as a role model: effects on trust, job satisfaction, and performance of salespeople', Academy of Marketing Science Journal, Vol. 25, No. 4, pp.319-328. 
Ringle, C.M., Sarstedt, M. and Straub, D.W. (2012) 'A critical look at the use of PLS-SEM in MIS quarterly’, MIS Quarterly, Vol. 36, No. 1, pp.iii-xiv.

Rizzo, J.R., House, R.J. and Lirtzman, S.I. (1970) 'Role conflict and ambiguity in complex organizations', Administrative Science Quarterly, Vol. 15, No. 2, pp.150-163.

Rosenberg, M. (1956) 'Misanthropy and political ideology', American Sociological Review, Vol. 21, No. 6, pp.690-695.

Rosenthal, R. and Rosnow, R.L. (1991) 'Essentials of behavioral research: Methods and data analysis', McGraw Hill, Boston, MA.

Schoorman, F.D., Mayer, R.C. and Davis, J.H. (1996) Empowerment in Veterinary Clinics: The Role of Trust in Delegation, Paper presented at the 11th Annual Meeting of the Society for Industrial and Organizational Psychology, San Diego, CA.

Schoorman, F.D., Mayer, R.C and Davis, J.H. (2007) 'An integrative model of organizational trust: past, present, and future', The Academy of Management Review, Vol. 32, No. 2, pp.344-354.

Sims, R.L. (2000) 'The relationship between employee attitudes and conflicting expectations for lying behavior', Journal of Psychology, Vol. 134, No. 6, pp.619-633.

Tan, H.H. and Tan, C.S.F. (2000) 'Towards the differentiation of trust in supervisor and trust in organization', Genetic, Social, and General Psychology Monographs, Vol. 126, No. 2, pp.241-260.

Tett, R.P. and Meyer, J.P. (1993) 'Job satisfaction, organizational commitment, turnover intention: path analyses based on meta-analytic findings', Personnel Psychology, Vol. 46, No. 2, pp.259-293.

Thompson, J.D. (1967) Organizations in Action, McGraw Hill, New York.

Thornton, G.C. (1980) 'Psychometric properties of self-appraisals of job performance', Personnel Psychology, Vol. 33, 264-271.

Uslaner, E.M. (2002) The Moral Foundations of Trust, Cambridge University Press, Cambridge, UK.

Vandenabeele, W. (2009) 'The mediating effect of job satisfaction and organizational commitment on self-reported performance: More robust evidence of the PSM-performance relationship', International Review of Administrative Science, Vol. 75, No. 1, pp.11-34.

Wagner, C.H. (1982) 'Simpson's paradox in real life', The American Statistician, Vol. 36, No. 1, pp.46-48.

Ward, P.R., Mamerow, L. and Meyer, S.B. (2014) 'Interpersonal trust across six Asia-Pacific countries: testing and extending the 'high trust society' and 'low trust society' theory", PLoS ONE, Vol. 9, No. 4, pp.1-17, e95555.

Yamaguchi, H., Brase, G.L and Yama, H. (2014) 'Two methods to measure the level of trust of Americans and Japanese: a cross-cultural study', SAGE Open October-December, 1-7.

Yang, J. (2005) 'The role of trust in organizations: Do foci and bases matter?' (Doctoral dissertation). Retrieved from ProQuest Dissertations and Theses.

\section{Notes}

1 See Reeskens and Hooghe (2008) for a good discussion of measurement equivalence of generalised trust in comparative research.

2 Index of country scores available at: http://www.jdsurvey.net/

3 See details of multi-group analysis by Ned Kock at http://warppls.blogspot.com.tr/2013/06/ multi-group-analyses-with-warppls.html 


\section{APPENDIX-1}

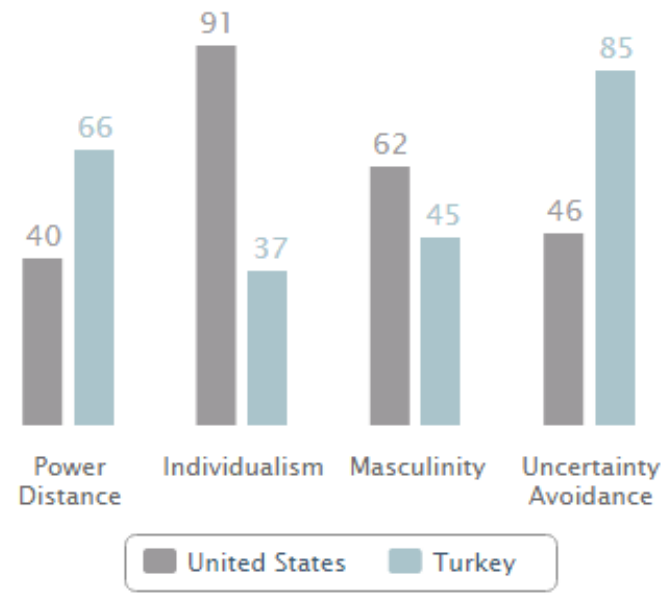

Source: http:/geert-hofstede.com/ 